\title{
CASE REPORT Spinal cord infarction in carriers of methylenetetrahydrofolate reductase-polymorphism-like unique risk factor: report of two cases
}

\author{
V Tejero-Fernández ${ }^{1}$, I Fernández-Rodríguez ${ }^{1}$, MD Membrilla-Mesa ${ }^{1}$ and M Arroyo-Morales ${ }^{2}$
}

Study design: A case report.

Objective: To present two cases of spinal cord infarction (SCI) in carriers of the C677T methylenetetrahydrofolate reductase (MTHFR) polymorphism.

Setting: Physical Medicine and Rehabilitation Department, Section for Rehabilitation and Traumatology, Hospital Virgen de las Nieves, Granada, Spain.

Methods: Two cases are presented, one with $\mathrm{SCl}$ at the $\mathrm{C} 7$ level American Spinal Injury Association (ASIA) A and one at the C5 level (ASIA A). One patient presented an acute onset of tetraplegia and the other a centromedular syndrome. In both cases the patients were carriers of the MTHFR polymorphism, which is a unique risk factor.

Results: Increased blood levels of homocysteine related to mutation of the MTHFR gene increase the risk of a thrombotic episode, triggering the development of $\mathrm{SCl}$. These two cases increase the limited number reported in the recent literature regarding MTHFR polymorphism carriers suffering from thrombotic SCl.

Conclusion: MTHFR mutation can be considered a risk factor for thrombotic SCl, but it is not the sole risk factor. We propose that a consensus regarding the inclusion of anticoagulation treatment after confirmation of the diagnosis in these patients is needed.

Spinal Cord (2014) 52, S8-S10; doi:10.1038/sc.2014.129

\section{INTRODUCTION}

Spinal cord infarction (SCI) is a rare but serious event with diverse aetiology, including vascular, inflammatory and genetic abnormalities. ${ }^{1}$ The neurologic presentation is abrupt and defined by the vascular territory involved. Methylenetetrahydrofolate reductase (MTHFR) mutations have been reported to be a risk factor for arterial and venous thrombosis. ${ }^{2}$ However, there are few published cases of carriers of MTHFR polymorphisms presenting with SCI.

\section{Case reports}

Case 1. A 28-year-old woman with a history of epilepsy presented with a sudden onset of cervical and interscapular pain in addition to a progressive general weakness of the extremities, paraesthesia and acute retention of urine. Preliminary neurological assessment revealed complete sensory and motor impairment in the lower extremities and distal motor impairment with normal sensory testing in the upper extremities. Magnetic resonance imaging (MRI) of the spine showed a hyperintense anterior and central band on T2-weighted images from C3 to T6 (Figures 1-4), which suggested SCI. Anticoagulation therapy was started after the diagnosis. Genetic tests documented homozygosity for the MTHFR C677T mutation, but normal levels of homocysteine. She was admitted to the Rehabilitation department, where she was treated with physical therapy and occupational therapy for 6 months. However, the strength of her extremities did not improve, and she remained tetraplegic American Spinal Injury Association (ASIA) A, C7 2 years later.

Case 2. A previously healthy 17-year-old male was admitted to our Emergency department with sudden cervical pain and upper extremity weakness. During the following hours, the weakness extended to the lower extremities, and the patient experienced respiratory arrest. Orotracheal intubation and mechanical ventilation were performed. Initial neurological examination showed complete flaccid tetraplegia (ASIA A, C5). The patient also presented acute retention of urine. MRI of the cervical spine revealed centromedular and anterior injury that was hyperintense from $\mathrm{C} 2$ to $\mathrm{C} 7$ on $\mathrm{T} 2-$ weighted images, which is characteristic for SCI (Figures 5 and 6). Anticoagulation therapy was started with low-molecular-weight heparin. Over the next 15 days, the symptoms changed to a central cord syndrome. In the intensive care unit, the patient improved his sensorimotor functions in the lower extremities. However, his arm strength remained unchanged. His respiratory function improved, and he was extubated and progressively disconnected from mechanical ventilation. Laboratory coagulation testing revealed heterozygosis for the MTHFR C677T mutation, and his blood homocysteine levels were within normal limits. After 2 months, he was transferred to our

${ }^{1}$ Physical Medicine and Rehabilitation Department, Section Rehabilitation and Traumatology, Hospital Virgen de las Nieves, Granada, Spain and ${ }^{2}$ Physical Therapy Department, Instituto Investigación Biosanitaria (IBIS), University of Granada, Granada, Spain

Correspondence: Dr V Tejero-Fernández, Hospital De Rehabilitación y Traumatología (Virgen de las Nieves), Servicio de Rehabilitación, Carretera de Jaen s/n, Granada CP 18013, Spain. 


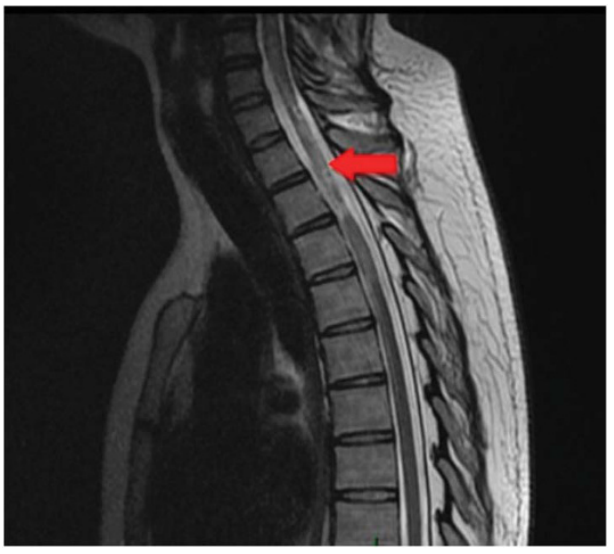

Figure $1 \mathrm{MRI}$, magnetic resonance imaging: a hyperintense anterior and central band on a T2-weighted image from C3 to T6.

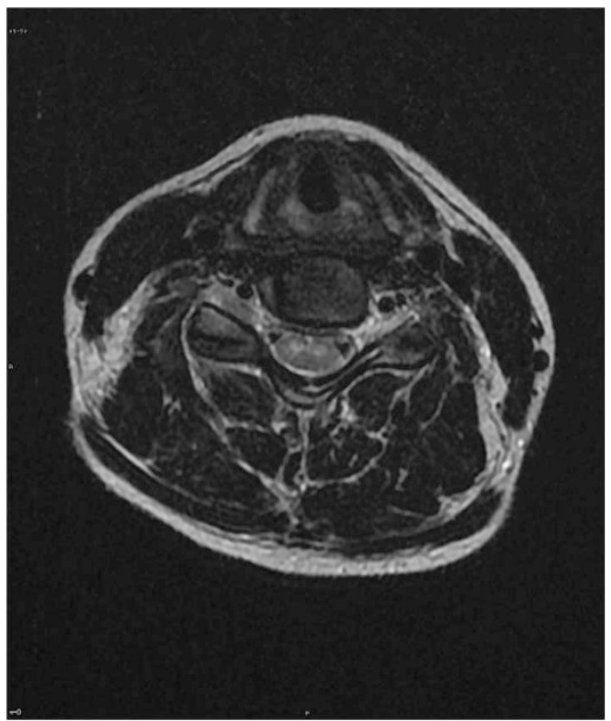

Figure 2 MRI: hyperintense anterior band on a T2-weighted axial image.

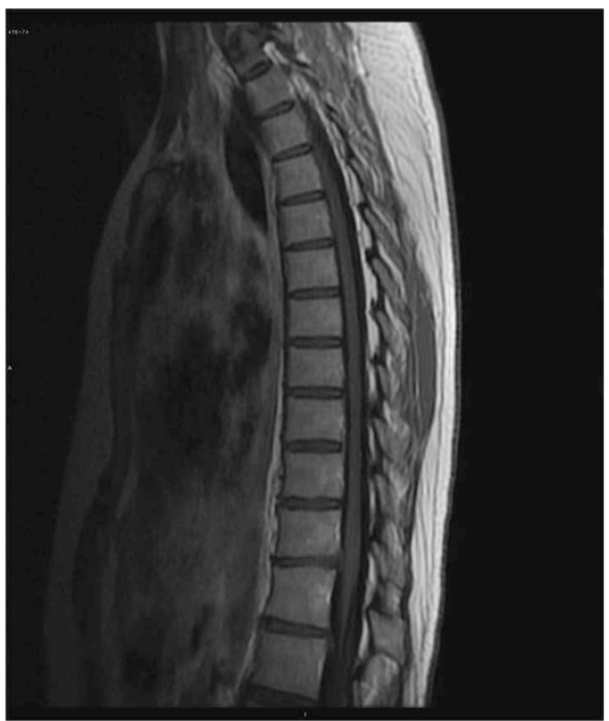

Figure $3 \mathrm{MRI}$ with contrast but without significant contrast enhacement.

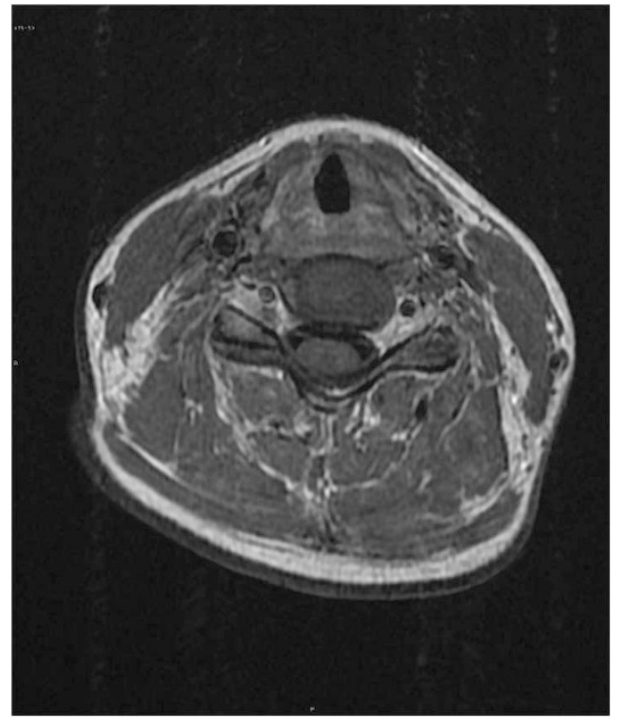

Figure $4 \mathrm{MRI}$ on axial image with contrast but without significant contrast enhacement.

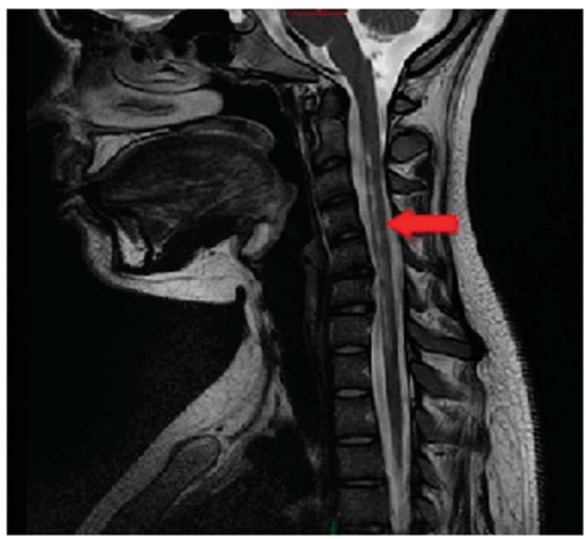

Figure $5 \mathrm{MRI}$ : centromedular and anterior injury that is hyperintense from $\mathrm{C} 2$ to $\mathrm{C} 7$ on a T2-weighted image, which is characteristic of $\mathrm{SCl}$.

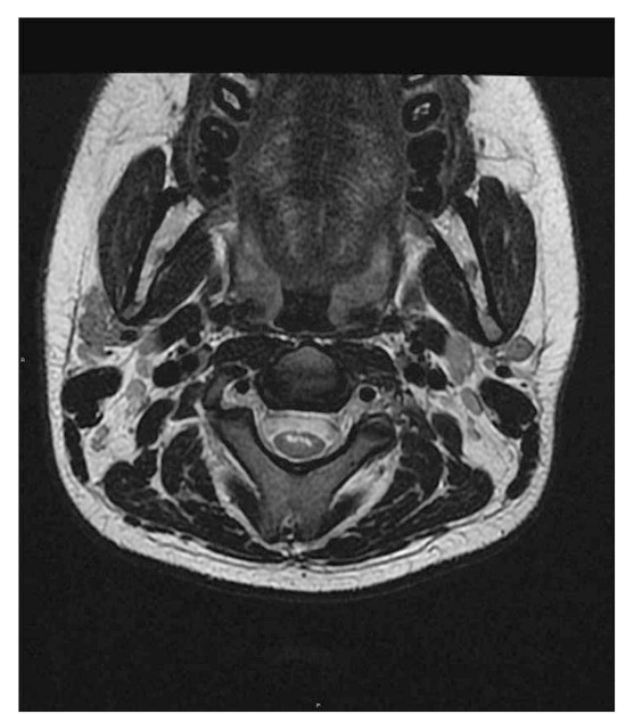

Figure 6 MRI: centromedular and anterior injury on a T2-weighted axial image. 
Table 1 A collection of the reported cases of spinal cord infarction in carriers of an MTHFR polymorphism, including the present report (fourth and fifth cases in the table)

\begin{tabular}{|c|c|c|c|c|c|c|c|c|}
\hline $\begin{array}{l}\text { Case } \\
\text { no. }\end{array}$ & Year & Author & Age-sex & $\begin{array}{l}\text { Location of } \\
\text { infarction }\end{array}$ & Mutation & $\begin{array}{l}\text { Other risk factors } \\
\text { for infarction }\end{array}$ & Follow-up & $\begin{array}{l}\text { Homocysteine } \\
\text { levels }\left(\mu \mathrm{mol}^{-1}\right)\end{array}$ \\
\hline 1 & 1998 & Mercier et al. ${ }^{6}$ & $41-\mathrm{F}$ & $\begin{array}{l}\text { Not } \\
\text { reported }\end{array}$ & $\begin{array}{l}\text { Homozygous for the MTHFR } \\
677 T \text { polymorphism }\end{array}$ & $\begin{array}{l}\text { Heterozygous for the } \\
\text { PT } 20210 \text { A allele. } \\
\text { Smoker } \\
\text { Oral-contraceptive } \\
\text { user }\end{array}$ & Not reported & Not reported \\
\hline 2 & 2006 & Mahfouz et al. ${ }^{2}$ & $51-\mathrm{F}$ & T10-T11 & $\begin{array}{l}\text { Homozygous for the MTHFR } \\
677 T \text { polymorphism }\end{array}$ & None & Paraplegic & 12 \\
\hline 3 & 2011 & Meinicke et $a l^{3}$ & $13-\mathrm{M}$ & T4-T5 & $\begin{array}{l}\text { Homozygous for the MTHFR } \\
\text { A222V polymorphism }\end{array}$ & None & $\begin{array}{l}\text { Able to walk unaided } \\
\text { Normal bladder function }\end{array}$ & 13.7 \\
\hline 4 & 2011 (present report) & Tejero-Fernández et al. & $28-F$ & C3-T6 & $\begin{array}{l}\text { Homozygous for the MTHFR } \\
677 T \text { polymorphism }\end{array}$ & None & Tetraplegic & 11 \\
\hline 5 & 2012 (present report) & Tejero-Fernández et al. & $17-\mathrm{M}$ & $\mathrm{C} 2-\mathrm{C} 7$ & $\begin{array}{l}\text { Heterozygous for the MTHFR } \\
677 T \text { polymorphism }\end{array}$ & None & $\begin{array}{l}\text { Able to walk unaided } \\
\text { Paralysis in upper limbs }\end{array}$ & 8 \\
\hline
\end{tabular}

Rehabilitation department, where he stayed for 3 months. At the time of publication, he had regained normal bladder function and was walking independently, although paralysis of the upper limbs persisted without improvement in strength.

In both cases, neuroimaging studies of the brain were normal. Vascular malformation of the spinal cord was ruled out, and no systemic arteritis, aortic thrombosis or dissection, or emboli were found. Other procoagulation genetic disorders were excluded. Our 2 patients had no personal or family history of procoagulant or haemorrhagic disorders.

\section{DISCUSSION}

A review of the literature of all reported cases of SCI in patients who are carriers of MTHFR polymorphisms was performed, and only three cases were found (Table 1). SCI represents only $5-8 \%$ of acute myelopathies. ${ }^{3}$ The C677T polymorphism in MTHFR has been reported to be associated eventually with elevation of homocysteine levels. ${ }^{4}$ However, the cases of the present report had normal levels of homocysteine. This could suggest another additional mechanism to cause a thrombotic episode, assuming always that this mutation may not be the definitive cause of the ischaemia in our patients. There are only three reported cases in the literature that describe patients who were carriers of MTHFR polymorphisms and presented with SCI. From 2011 to 2013, we admitted to our Rehabilitation department two cases of SCI with a mutation in MTHFR that appeared to be the sole risk factor of thrombotic disease.

The normal homocysteine range in our Haematology laboratory is 4-14 $\mathrm{moll}^{-1}$; according to Meinicke et al., ${ }^{3}$ blood levels of homocysteine range from 5 to $11.7 \mu \mathrm{moll}^{-1}$. Selhub et al. ${ }^{5}$ have concluded that the reference range for blood homocysteine is 4.3-15.3 $\mu \mathrm{moll}^{-1}$ for males and 3.3-11.6 $\mathrm{moll}^{-1}$ for females. The case reported by Meinicke et al. ${ }^{3}$ had a history of leg strain after a rotating kick movement in a competitive taekwondo fight that was considered together with MTHFR mutation as a possible cause of the SCI.
While all of the cases previously described in the literature were homozygous for the mutation, our second reported case is the only reported case that was heterozygous for the mutation.

Although the mutation in the MTHFR gene was the only risk factor for thrombosis detected in our patients, we cannot conclude that this mutation is the cause of the SCI. At the time of publication, the patients continued to receive antiaggregation therapy daily.

\section{CONCLUSIONS}

These cases support the MTHFR mutation as a possible cause of SCI. This study presents the first reported case of a heterozygous carrier of an MTHFR mutation suffering from SCI. We believe that after confirmation of the diagnosis the appropriate anticoagulation therapy should be initiated and that once clinical stability has been reached intensive rehabilitation must be started as soon as possible to minimise the potential consequences of SCI.

\section{CONFLICT OF INTEREST}

The authors declare no conflict of interest.

1 Rubin MN, Rabinstein AA. Vascular diseases of the spinal cord. Neurol Clin 2013, 31: 153-181.

2 Mahfouz RA, Otrock ZK, Kankan ZM, Sawaya RA, Taher AT. Homozygous methylenetetrahydrofolate reductase C677T mutation in a woman with spinal cord infarction. Eur J Neurol 2006; 13: e4.

3 Meinicke H, Moske Eick O, Sitzberger AN, Zieger B, Kirschner J. Anterior spinal artery syndrome in a 13-year-old boy 8 days after taekwondo-fight: vascular obliteration due to vessel lesion or thrombophilia? Klin Padiatr 2011; 223: 182-186.

4 Li P, Qin C. Methylenetetrahydrofolate reductase (MTHFR) gene polymorphisms and susceptibility to ischemic stroke: a meta-analysis. Gene 2014; 535: 359-364.

5 Selhub J, Jacques PF, Rosenberg IH, Rogers G, Bowman BA, Gunter EW et al. Serum total homocysteine concentrations in the third National Health and Nutrition Examination Survey (1991-1994): population reference ranges and contribution of vitamin status to high serum concentrations. Ann Intern Med 1999; 131: 331-339.

6 Mercier E, Quere I, Campello C, Mares P, Gris JC. The 20210A allele of the prothrombin gene is frequent in young women with unexplained spinal cord infarction. Blood 1998; 92: 1840-1841. 